\title{
Was there unmet mental health need after the September 11, 2001 terrorist attacks?
}

Abstract Background This study examined the use of professionals for mental health problems among New York City residents who were directly affected by the September 11, 2001 terrorist attacks on the World Trade Center (WTC) or had a probable diagnosis of post-traumatic stress disorder (PTSD) or depression in its aftermath. Correlates of help seeking from professionals for mental health problems after the attacks and barriers to care were also assessed. Method Data were from a random digit dial telephone survey of 2,752 adults representative of the Greater New York Metropolitan area conducted 6 months after the September 11 terrorist attacks. Results Fifteen percent of those directly affected and $36 \%$ of those with probable PTSD or depression sought help from a professional for a mental health problem after the attacks. There was little new utilization of professionals for mental health problems after the attacks among persons who were not already

J. Stuber, $\mathrm{PhD}$ - J. A. Boscarino, $\mathrm{PhD}, \mathrm{MPH}$

The Division of Health and Science Policy

The New York Academy of Medicine

New York, NY

J. Stuber, PhD ( $\square)$

Robert Wood Johnson Health and Society

Columbia University

International Affairs Building

$420 \mathrm{~W}$ 118th Street, 8th Floor

New York, (NY) 10027, USA

E-Mail: jstuber@nyam.org

S. Galea, MD, DrPH

Center for Urban Epidemiologic Studies

The New York Academy of Medicine

New York, (NY) USA

S. Galea, MD, DrPH

Department of Epidemiology

University of Michigan

Ann Arbor, (MI) USA

M. Schlesinger, $\mathrm{PhD}$

School of Epidemiology and Public Health

Yale University

N New Haven, (CT) USA receiving care prior to September 11. Barriers that prevented people from seeking help for mental health problems 6 months after the September 11 attacks included traditional barriers to care (e.g., cost) and barriers that are unique to the post-disaster context (e.g., the belief that others need the services more than oneself). Conclusions This study suggests that there was potential unmet mental health need in New York City 6 months after the September 11 attacks on the WTC, but these findings should be tempered by research showing an apparent decrease in populationrates of PTSD. In the aftermath of a disaster, interventions should target persons with mental health needs who were not previously seeking help from a professional for a mental health problem.

Key words unmet mental health need - terrorism - posttraumatic stress disorder - depression

\section{Introduction}

In the United States, a substantial proportion of persons with psychiatric morbidity do not receive appropriate mental health care $[1,2]$. The burden of unmet mental health need became a particular concern in the aftermath of the September 11, 2001 terrorist attacks on the World Trade Center (WTC) and the Pentagon. Previous post-disaster studies suggest that survivors of major disasters develop psychiatric disorders after these events including posttraumatic stress disorder (PTSD), depression, anxiety, panic and other mental health disorders $[3,4]$. Research after the September 11 attacks found an increase in psychological symptoms after the attacks. Stress, PTSD and depression, were highly prevalent in the U.S. general population and particularly among New York City (NYC) residents [5-7]. Subsequent research found a resolution of probable PTSD 6-9 months 
after September 11 but that overall, the prevalence of PTSD symptoms decreased by only one-third [8].

While the utilization of health services for mental health problems has been documented following disasters [9-13] and numerous studies have examined unmet mental health need in less dire times [14-16], little is known about such unmet need following a disaster. This is an important area of inquiry because the response of the health system to mental health problems may need to be more proactive after a disaster. It is also possible that barriers to treatment for mental health problems after disasters are different from traditional barriers to mental health treatment in less critical times. Impediments to mental health treatment in general have been described. They include: concerns about cost, lack of time to seek care, stigma, or feelings among affected persons that they can take care of mental health symptoms themselves [17]. By contrast, the reasons why people may not access services after a major disaster are less well known.

A reluctance to utilize services for mental health problems after a disaster has been reported, although the reasons for this reluctance are unclear [18-20]. Oftentimes, studies of service utilization for mental health problems after a disaster fail to ask about barriers to mental health treatment and do not consider barriers that may be unique to a post-disaster context. One study suggested that individuals may avoid formal mental health services out of concern that accessing these services may revive disturbing images and memories of the traumatic event [21]. Grieving individuals who develop psychological symptoms after a disaster may lack awareness that these symptoms are a potentially treatable mental health problem. It is also possible that the devastation of the September 11 attacks may have led to the perception that there were not enough mental health services to help those affected by the event. Thus, there may have been reluctance to claim services out of a concern for taking the spot of someone who needed the services more.

Conversely, there are reasons why people may be more willing to access mental health services following a disaster. In NYC after the terrorist attacks, not unlike other post-disaster situations in the United States, there was a concerted public health effort to provide services for mental health problems to people who were personally affected by the event. The scope of this service provision was unprecedented. Project Liberty, the umbrella program under which many of these services were provided, provided outreach, public education about reactions to trauma, free short-term crisis counseling services and referrals to longer term specialized mental health treatment to persons in need $[22,23]$. Services offered by Project Liberty were an adjunct to services offered by the regular public mental health system in NYC in the aftermath of September 11. This effort may have re- sulted in a reduction in the traditional barriers to mental health treatment such as a lack of knowledge about the availability of services, awareness that one's problems may be due to a mental illness, and cost. It is also possible that the stigma surrounding mental illness was reduced after these attacks, both because of the increased awareness of the mental health consequences of the attacks and the widespread attribution of potential psychological symptoms to a specific event rather than to individual characteristics [24].

In this study, we examined the use of professionals for mental health problems in three groups. First, because we were interested in identifying markers of real need since the September attacks we examined the use of professionals for mental health problems among persons with probable PTSD and depression. Second, because persons who were directly affected by the attacks were at higher risk for psychological sequelae after the attacks than persons who did not have direct exposure to the event, we were interested in the use of professionals for mental health problems by this group. As described, these individuals were targeted by social service agencies after the attacks. We eliminated from this group persons with PTSD and depression since the attacks so that we could identify unique determinants of the use of professionals for mental health problems for this group. Third, for comparison purposes we were interested in the utilization of professionals for mental health problems among persons who did not meet either of these two criteria. We expected rates of service utilization to be substantially lower in this group compared to the other two groups. In this study, we also identified the primary reasons why persons did not seek treatment from professionals for mental health problems after the attacks and the factors associated with decisions to seek help.

This is one of a handful of studies to examine the issue of unmet mental health need in a post-disaster context as well as barriers to treatment that may be unique to such a post-disaster context. Identifying such potential need and barriers to seeking services after a major disaster is important to guide effective public health planning.

\section{Methods}

\section{Data collection}

Analyses are based on telephone interviews with 2,752 adults (over the age of 17) living in households in the NYC metropolitan area between March 25 and June 25, 2002. The sampling frame for the survey included all adults in the following contiguous geographic areas: New York City and Nassau, Westchester, Suffolk, and Rockland counties in New York State; Hudson, Essex, Bergen, Passaic, Union, Middlesex, Monmouth, Morris, and Somerset counties in New Jersey, and Lower Fairfield county in Connecticut. The entire sampling frame was divided into four concentric zones, with oversampling in the zones closer to the World Trade Center. 
Random digit dial telephone interviews were used to sample participants. If more than one adult in the household was eligible for participation the last birthday procedure was used to select the respondent. We dialed a total of 31,672 phone numbers during the study. Among these, 8,397 were identified as not in service, and 6,736 numbers were not valid for other reasons (e.g., fax lines or businesses). Out of the 16,539 valid numbers, 4,231 were not answered on any of the ten calls. From the remaining 12,308 numbers, 1,026 were never answered except by answering machines (messages were left), and 932 numbers were not eligible for other reasons (mainly languages other than English, Spanish \& Chinese). We spoke with a total of 10,350 households; 3,216 were callbacks still not reached at the end of the study to complete the screening for eligibility. Among the 7,134 households with a resolved contact, 2,988 refused to complete the initial screening for the interviewing. Among the 4,146 screened, 315 persons screened out of the survey, and 3,831 were eligible for the study. There were 854 who were not interviewed because the quota for their gender and zone had been filled. We completed interviews with 2,711 of the remaining 2,977 persons, 127 refused after qualifying, and 139 were in call-back status at study completion. The overall cooperation rate for the survey, calculated according to industry standards, was $56 \%$. This cooperation rate is based on the sum of the number of completed interviews, quota outs and screen-outs (i.e., $2,711+854+315$ ) divided by the sum of completed interviews, quota outs, screen outs, refusals, and premature terminations (i.e., 2,711 + 854+ $315+2,988+127)$ [25]. Sampling weights were developed and applied to the data to correct potential selection bias related to the number of household telephones, persons in the household, and over-sampling.

All interviews were conducted by trained interviewers using a computer-assisted telephone interview system. Interviews were available in English, Spanish and Chinese and took approximately 35 minutes to complete. The Institutional Review Board of the New York Academy of Medicine reviewed and approved this study and informed consent of all respondents was obtained. Respondents were asked questions using a structured questionnaire.

\section{Instrument}

For our measure of help seeking from professionals for mental health problems, we adopted questions from the National Comorbidity Study (NCS) [2]. We asked participants if they received counseling from a list of helping professionals for problems with their emotions or nerves or for problems with use of alcohol or drugs in the 6 months before the September 11 attacks and in the 6 months following it. Psychiatrists, psychologists, physicians, nurses counselors, social workers and self-help groups, such as Alcoholics Anonymous or Narcotics Anonymous were considered helping professionals. We also asked participants if they saw a spiritual advisor (e.g., minister, priest or rabbi) for these problems, but did not consider them professionals and therefore, did not include them in this analysis.

Study participants provided information about their demographic characteristics (age, race, gender, education) and factors that may be important to whether people seek help from professionals for mental health problems including: marital status, income, physical health status, co-morbid physical health conditions, a past history of physical or sexual abuse, health insurance status and having a regular doctor. We asked respondents if they had mental or emotional problems in the 12 months prior to the attacks.

For the purpose of these analyses, participants were considered to be directly affected by the event if they were inside the WTC complex during the attacks, if they were injured during the attacks, if they lost possessions or property as a result of the attacks, if a friend or relative killed during the attacks, if they lost a job due to the attacks, or were involved in the rescue efforts.

Probable PTSD since the September 11 attacks was assessed using a scale designed for administration by trained nonclinical interviewers during a structured telephone survey based on the DSM-IV criteria [26]. The PTSD scale has a coefficient of agreement with clinician-administered structured clinical interviews of 0.71 for current PTSD [27, 28]. The PTSD scale assesses the presence of criterion $\mathrm{B}, \mathrm{C}$ and $\mathrm{D}$ symptoms and determines content for contentspecific PTSD symptoms (e.g., content of dreams or nightmares). For the purpose of this analysis, we focused on probable PTSD related to the attacks so all re-experiencing symptoms (criterion B) and all content-specific avoidance symptoms (criterion $\mathrm{C}$ ) were required to be related it. In addition, we asked persons who had symptoms of PTSD about diminished functioning specifically, if the problems they were having interfered with their ability to live their life. To assess probable depression since the attacks, we used an adapted version of the SCID's major depressive episode interview from the non-patients interview schedule version [29], which has been used with other populations [30, 31]. Following DSM-IV guidelines [26], respondents met criteria for depression if they had five or more symptoms for at least two-weeks since the attacks. For further details regarding the measures used in this assessment we refer the reader to previous publications $[6,8]$.

In addition, we asked persons who did not seek professional help for a mental health problem in the 6 months after the attacks if they considered it and persons who did receive mental health services if they waited two or more weeks to do so. Study participants who reported that they did not seek services but that they had considered it were asked about the barriers to accessing mental health treatment. We asked about a list of potential reasons for not seeking treatment including: stigma related concerns (concerns about what others think, concerns about feeling badly of self), altruistic concerns (feelings that other people needed the help more than oneself), financial concerns, not knowing how to get help, and not having the time to get help. We developed this list of barriers from prior literature and revised this list during several days of pretesting of the instrument. Participants could select multiple reasons. In addition, we asked respondents to list any other reason for not accessing mental health services and coded those responses.

\section{Statistical analyses}

We used two-tailed chi-square tests to compare the demographic characteristics of three independent groups: respondents with probable PTSD or depression since the September 11 attacks, respondents who were directly affected by the attacks but who did not have probable PTSD or depression, and all other respondents who did not meet either of these criteria. In analyses stratified by these three groups, we examined the proportion of respondents who received help from a professional for a mental health problem in the 6 months following the attacks, who waited two or more weeks prior to seeking this help, who did not receive professional help in the 6 months after the attacks but considered it, and who did not receive professional help and did not consider it.

Bivariate relations were assessed to determine factors associated with counseling from professionals for mental health problems in the 6 months following the September 11 attacks, but, with one exception, they are not shown here because they were not appreciably different from the multivariate results. Because the vast majority of respondents who sought help from professionals for mental health problems were in counseling in the 6 months prior to September 11, we created a separate bivariate table underscoring the importance of this association, but do not include the variable measuring prior counseling in multivariable models because of the distortion of the odds ratios that results when doing so. Multivariable logistic regression was used to assess predictors of counseling for mental health problems in the 6 months after the terrorist attacks among respondents with probable PTSD or depression, respondents who were directly affected by the attacks but who did not have probable PTSD or depression, and among all other respondents who did not meet either of these criteria. We note that these models are not appreciably different from multivariate models estimated with the prior counseling variable included.

Among the respondents who did not receive counseling from a professional for a mental health problem in the 6 months after the attacks but considered it we compared reasons as to why these respondents did not receive professional help in the three groups of interest. Open-ended responses were coded and are reported. 
Weights were applied to account for the sampling fraction. Standard errors were calculated and significance determined using SUDAAN software to account for the complex survey design.

\section{Results}

\section{Characteristics of study populations}

The demographic characteristics of the respondents included in these analyses and of residents of the NYC metropolitan area, according to the U.S. Census, were comparable and there were no appreciable differences between the population sampled and the underlying population [32]. In this sample 54\% were female, $53 \%$ were white, $16 \%$ were African American, $21 \%$ were Hispanic, 5\% were Asian, 50\% reported an annual income between $\$ 20,000$ and $\$ 75,000$ and $51 \%$ were married.

Table 1 compares the demographic characteristics of respondents who had probable PTSD or depression since the September 11 attacks, to respondents directly affected but who did not meet the criteria for probable PTSD or depression, to all other respondents who did not meet either criterion. Persons with probable PTSD or depression were more likely to be aged 25-44, to be female, to have had a past history of physical or sexual abuse, to have had a previous mental health problem, to not be married, to not have health insurance, and to have received counseling in the 6 months prior to the terrorist attacks compared to all other respondents. Persons directly affected by the attacks were more likely to be between the ages of 25-44 and had higher incomes relative to all other respondents.

\section{Use of professionals for mental health problems}

Overall, $9 \%$ of the sample sought help from a professional for a mental health problem in the 6 months following the September 11 attacks. Figure 1 shows that persons with probable PTSD or depression were more likely to seek help from a professional for a mental health problem than were respondents in the other two groups. However, $64 \%$ of persons with probable PTSD or depression did not seek help from a professional for a mental health problem since the event despite the fact that the majority of respondents reported diminished functioning (70\% of respondents with probable PTSD reported diminished functioning). Eighty-five percent of persons who were directly affected by the attacks did not receive counseling from a professional for a mental health problem in the 6 months after the September 11 attacks although $45 \%(278 / 616)$ of this group reported at least one symptom of PTSD or depression since then. Among persons who did not seek help from a professional for a mental health problem in the 6 months following the attacks, $17 \%$ with probable PTSD or depression, $6 \%$ of persons who were directly affected by the attacks, and $3 \%$ of the remainder of the sample considered it. Among persons who did receive help from a professional for a mental health problem, $13 \%$ with probable PTSD or depression, $4 \%$ who were directly affected, and $1 \%$ of the remainder of the sample waited two or more weeks to seek care.

\section{Correlates of seeking help from professionals for mental health problems}

Table 2 shows that the receipt of mental health services prior to September was highly predictive of the use of professionals for mental health problems after September 11. Among respondents with probable PTSD or depression only $14 \%$ of those who received services after the attack had not received services in the 6 months prior to it. Consistent with the observed strength of this association we note that among all respondents who received services after September $11(n=447), 335$ or $75.0 \%$ were already receiving services before the event. Because previous counseling was so highly correlated with the use of mental health services after September 11 we did not include it in the final multivariable models designed to identify other factors associated with mental health counseling 6 months after the event. We note that additional factors associated with counseling identified in the multivariable models described below did not differ when the prior counseling variable was included in these models.

Table 3 shows factors associated with an increased probability of seeking help from professionals for mental health problems in the 6 months after the terrorist attacks among respondents with probable PTSD of depression, among persons directly affected by the attacks who did not have PTSD or depression, and among respondents who did not meet either of these criteria. Among persons with probable PTSD or depression, having an annual household income of $\$ 30,000-\$ 75,000$ as compared to an annual household income of less than $\$ 30,000(\mathrm{OR}=2.48,95 \% \mathrm{CI}=$ $(1.03,5.95))$ and having a previous mental health problem before September $11(\mathrm{OR}=5.64,95 \% \mathrm{CI}=$ $(2.67,11.90))$ were associated with the assistance of professionals for mental health problems in the 6 months after September 11. Among persons directly affected by the attacks but who did not have probable PTSD or depression, having a mental health problem prior to the event $(\mathrm{OR}=16.75,95 \% \mathrm{CI}=(5.94$, $27.24))$, having a regular doctor $(\mathrm{OR}=3.50,95 \% \mathrm{CI}=$ $(1.24,9.87))$ and being in fair or poor as compared to excellent, very good, or good physical health $(\mathrm{OR}=$ $3.16,95 \% \mathrm{CI}=(1.13,8.85))$ were associated with the receipt of counseling in the 6 months following the terrorist attack. 
Table 1 Characteristics of respondents with probable PTSD or depression, those directly affected by the attack but who do not have PTSD or depression and all others $^{\mathrm{a}}$

\begin{tabular}{|c|c|c|c|c|c|c|c|}
\hline \multirow[b]{2}{*}{ Age } & \multicolumn{2}{|c|}{$\begin{array}{l}\text { Probable PTSD or } \\
\text { depression }(n=419)\end{array}$} & \multicolumn{2}{|c|}{$\begin{array}{l}\text { Directly affected }{ }^{b} \\
\text { with no PTSD or } \\
\text { depression }(n=616)\end{array}$} & \multicolumn{2}{|c|}{$\begin{array}{l}\text { All other respondents } \\
(n=1,719)\end{array}$} & \multirow{2}{*}{$\begin{array}{c}p \text {-value } \\
<0.0001\end{array}$} \\
\hline & & & & & & & \\
\hline $18-24$ & 40 & 17.3 & 53 & 10.9 & 168 & 13.8 & \\
\hline $25-44$ & 214 & 49.2 & 323 & 48.8 & 728 & 41.9 & \\
\hline $45-64$ & 140 & 30.6 & 184 & 32.4 & 530 & 31.1 & \\
\hline $65+$ & 21 & 2.9 & 50 & 7.9 & 270 & 13.2 & \\
\hline \multicolumn{7}{|l|}{ Race } & 0.003 \\
\hline White & 229 & 47.2 & 370 & 64.6 & 993 & 53.9 & \\
\hline Asian & 19 & 4.3 & 38 & 5.7 & 109 & 5.3 & \\
\hline African American & 59 & 16.9 & 80 & 13.9 & 252 & 16.2 & \\
\hline Hispanic & 91 & 27.9 & 93 & 13.0 & 281 & 20.2 & \\
\hline Other & 16 & 3.7 & 19 & 2.7 & 56 & 4.5 & \\
\hline \multicolumn{7}{|l|}{ Gender } & 0.10 \\
\hline Male & 172 & 39.1 & 292 & 46.0 & 809 & 47.8 & \\
\hline Female & 247 & 60.9 & 322 & 54.0 & 910 & 52.2 & \\
\hline \multicolumn{7}{|l|}{ Education } & 0.04 \\
\hline$<$ High School & 52 & 13.9 & 46 & 7.5 & 176 & 10.6 & \\
\hline High School Graduate & 168 & 51.2 & 236 & 45.2 & 713 & 47.9 & \\
\hline College Graduate & 198 & 34.7 & 329 & 47.3 & 817 & 41.6 & \\
\hline \multicolumn{7}{|l|}{ Income } & 0.0001 \\
\hline$<\$ 30,000$ & 112 & 26.7 & 114 & 14.6 & 416 & 23.9 & \\
\hline$\$ 30,000-\$ 75,000$ & 198 & 50.3 & 287 & 48.3 & 856 & 49.4 & \\
\hline$\$ 75,000+$ & 109 & 23.0 & 213 & 37.1 & 447 & 26.7 & \\
\hline \multicolumn{7}{|l|}{ Marital status } & 0.0002 \\
\hline Married & 140 & 38.4 & 291 & 57.5 & 751 & 52.4 & \\
\hline Not married & 278 & 61.6 & 319 & 42.5 & 961 & 47.6 & \\
\hline \multicolumn{7}{|l|}{ History of abuse } & $<0.0001$ \\
\hline No & 344 & 82.1 & 573 & 95.8 & 1,625 & 94.8 & \\
\hline Yes & 74 & 17.9 & 37 & 4.2 & 87 & 5.2 & \\
\hline \multicolumn{7}{|l|}{ Previous mental health problem } & $<0.0001$ \\
\hline No & 303 & 75.5 & 575 & 94.0 & 1,606 & 94.6 & \\
\hline Yes & 115 & 24.5 & 39 & 6.0 & 110 & 5.4 & \\
\hline \multicolumn{7}{|c|}{ Sought professional help for a mental health problem prior to September 11} & $<0.0001$ \\
\hline No & 281 & 71.2 & 541 & 90.3 & 1,525 & 90.5 & \\
\hline Yes & 138 & 28.8 & 73 & 9.7 & 194 & 9.6 & \\
\hline \multicolumn{7}{|l|}{ Health insurance } & 0.004 \\
\hline No & 78 & 20.3 & 68 & 9.4 & 169 & 12.3 & \\
\hline Yes & 338 & 79.7 & 538 & 90.6 & 1,517 & 87.7 & \\
\hline \multicolumn{7}{|l|}{ Regular doctor } & 0.39 \\
\hline No & 64 & 16.2 & 71 & 11.7 & 217 & 13.8 & \\
\hline Yes & 355 & 83.9 & 542 & 88.3 & 1,498 & 86.2 & \\
\hline \multicolumn{7}{|l|}{ Health status } & $<0.0001$ \\
\hline Excellent, very good, good & 300 & 66.2 & 542 & 89.9 & 1,430 & 83.8 & \\
\hline Fair, Poor & 280 & 16.2 & 71 & 10.1 & 280 & 16.2 & \\
\hline \multicolumn{7}{|l|}{ Co-morbid conditions } & 0.14 \\
\hline 0 & 954 & 59.0 & 345 & 55.8 & 954 & 59.0 & \\
\hline 1 & 423 & 23.7 & 158 & 27.6 & 423 & 23.7 & \\
\hline $2+$ & 331 & 17.3 & 107 & 16.6 & 331 & 17.3 & \\
\hline
\end{tabular}

aValues may not add to the reported $n$ 's due to missing data

${ }^{\mathrm{b}}$ Respondents were considered to be directly affected by the September 11 attacks if they were inside the WTC complex during the attacks, if they were injured during the attacks, if they lost possessions or property as a result of the

\section{Barriers to care}

Figure 2 shows the prevalence of barriers to receipt of mental health services among those who considered seeking care but decided not to by the three groups of interest. For example, among persons with probable PTSD or depression, $17 \%$ indicated they lacked knowledge about how to get help, $27 \%$ were concerned about stigma associated with mental illness, 39\% attacks, if a friend or relative was killed during the attacks, if they lost a job due to the attacks, or were involved in the rescue efforts

'Two-tailed chi-square test of significance

indicated that they did not have the money, $42 \%$ said they did not have the time, and $58 \%$ indicated that a reason they did not get help is because other people needed the services more than themselves (altruistic concerns). The results were comparable for the other two groups also.

Among the 168 people who considered seeking help from a professional for a mental health problem in the 6 months following the attacks but decided not 
Table 2 Association between receipt of counseling before September 11 and receipt of counseling after September 11 among respondents with probable PTSD or depression, those directly affected by the attack but who do not have PTSD or depression ${ }^{\mathrm{a}}$ and all others ${ }^{\mathrm{a}}$

\begin{tabular}{|c|c|c|c|c|c|c|c|c|c|c|c|c|}
\hline & \multicolumn{4}{|c|}{$\begin{array}{l}\text { Probable PTSD or depression } \\
(n=419)\end{array}$} & \multicolumn{4}{|c|}{$\begin{array}{l}\text { Directly affected } \\
(n=616)\end{array}$} & \multicolumn{4}{|c|}{$\begin{array}{l}\text { All other respondents } \\
(n=1,719)\end{array}$} \\
\hline & \multicolumn{2}{|c|}{$\begin{array}{l}\text { Received } \\
\text { counseling } \\
\text { after } \\
\text { September } 11\end{array}$} & \multicolumn{2}{|c|}{$\begin{array}{l}\text { Did not receive } \\
\text { counseling } \\
\text { after } \\
\text { September } 11\end{array}$} & \multicolumn{2}{|c|}{$\begin{array}{l}\text { Received } \\
\text { counseling } \\
\text { after } \\
\text { September } 11\end{array}$} & \multicolumn{2}{|c|}{$\begin{array}{l}\text { Did not receive } \\
\text { counseling } \\
\text { after } \\
\text { September } 11\end{array}$} & \multicolumn{2}{|c|}{$\begin{array}{l}\text { Received } \\
\text { counseling } \\
\text { after } \\
\text { September } 11\end{array}$} & \multicolumn{2}{|c|}{$\begin{array}{l}\text { Did not receive } \\
\text { counseling } \\
\text { after } \\
\text { September } 11\end{array}$} \\
\hline & $n$ & $\%$ & $n$ & $\%$ & $n$ & $\%$ & $n$ & $\%$ & $n$ & $\%$ & $n$ & $\%$ \\
\hline $\begin{array}{l}\text { Received counseling } \\
\text { before September } 11\end{array}$ & 122 & 89.4 & 16 & 10.6 & 58 & 81.2 & 15 & 18.8 & 155 & 75.5 & 39 & 24.5 \\
\hline $\begin{array}{l}\text { Did not receive counseling } \\
\text { before September } 11\end{array}$ & 45 & 14.4 & 236 & 85.6 & 31 & 4.1 & 510 & 95.9 & 36 & 1.9 & 1,489 & 98.1 \\
\hline$x^{2}$ & \multirow{2}{*}{\multicolumn{4}{|c|}{$\begin{array}{l}70.08 \\
<0.0001\end{array}$}} & \multirow{2}{*}{\multicolumn{4}{|c|}{$\begin{array}{l}101.4 \\
<0.0001\end{array}$}} & \multirow{2}{*}{\multicolumn{4}{|c|}{$\begin{array}{l}248.6 \\
<0.0001\end{array}$}} \\
\hline$p$-value ${ }^{\mathrm{b}}$ & & & & & & & & & & & & \\
\hline
\end{tabular}

${ }^{\text {a }}$ Respondents were considered to be directly affected by the September 11 attacks if they were inside the WTC complex during the attacks, if they were injured during the attacks, if they lost possessions or property as a result of the attacks, if a friend or relative was killed during the attacks, if they lost a job due to the attacks, or were involved in the rescue efforts

${ }^{\mathrm{b}}$ Two-tailed chi-square test of significance to, 48 respondents $(29 \%)$ offered additional explanations for why they did not seek care. The most common additional explanation was the respondent's belief that he/she could take care of him/ herself or could turn to family or friends for support (reported by 23 respondents or $14 \%$ of those who considered seeking professional help). Other less common responses included: feeling too depressed or overwhelmed to seek professional help, a lack of trust in mental health professionals, and fear of talking about the September 11 attacks.

\section{Discussion}

More than $60 \%$ of respondents with probable PTSD or depression did not seek help from a mental health professional after the attacks despite the fact that most of these respondents reported diminished functioning. Our findings underscore the importance of having a previously established therapeutic relationship in one's decision to seek services after a man-made disaster. Barriers to mental health treatment that prevented people from seeking professional aid 6 months following the incident included traditional barriers to care (e.g., stigma-related concerns) and barriers that are unique to the post-disaster context (e.g., felt that others needed the services more than oneself).

Our finding that a majority of respondents with PTSD or depression since the September 11 attacks did not receive mental health services in the 6 months after September 11 is consistent with a survey of New Yorkers conducted 3-6 months after the September 11 attacks that showed $27 \%$ of individuals with severe psychological symptoms were obtaining psychiatric treatment [33]. Several nationally representative stud- ies have shown that while the prevalence of psychiatric symptoms in the general population is high, a large proportion of persons who may benefit from mental heath interventions do not receive mental health care [14-16]. Our observation that $64 \%$ of persons who reported symptoms consistent with probable PTSD or depression did not receive services is on the lower end of the range of reported estimates of unmet mental health needs (ranging from $54 \%$ to $87 \%$ ) [14-16]. It is possible that the widespread availability of Project Liberty services and the open discussion about the potential psychological consequences of the attacks in the media after the attacks helped to increase the number of persons who received services.

The correlates of help seeking from a professional for a mental health problem identified in this study are consistent with the previous literature $[15,17,34]$. We found that persons with physical health problems were more likely to seek help for mental health problems [35]. One explanation for this is that persons with physical health problems are more likely to be linked to the health care system and as a result, may find it easier to access mental health services from their current health care provider or to get a referral for specialty care. In addition, physical health problems contribute to diminished functioning, which has been shown in many studies to be an important determinant of care seeking [15]. This may also explain why individuals with prior emotional problems, with a past history of sexual abuse, and who received counseling in the 6 months prior to September 11 were more likely to seek professional services after the attacks. The majority of people who sought mental health services after September 11 were already linked to the mental health care system before September 11. This is consistent with other studies of service utilization after the attacks showing little new utilization of mental health services [12, 13]. While 
Table 3 Factors affecting decisions to seek professional help after September 11 among respondents with probable PTSD or depression, those directly affected by the attack but who do not have PTSD or depression ${ }^{\mathrm{a}}$ and all others ${ }^{\mathrm{b}}$

\begin{tabular}{|c|c|c|c|c|c|c|}
\hline & \multicolumn{2}{|c|}{$\begin{array}{l}\text { Probable PTSD or depression } \\
(n=419)\end{array}$} & \multicolumn{2}{|c|}{$\begin{array}{l}\text { Directly affected with no PTSD } \\
\text { or depression }(n=616)\end{array}$} & \multicolumn{2}{|c|}{$\begin{array}{l}\text { All other respondents } \\
(n=1,719)\end{array}$} \\
\hline & Adj. OR & $95 \% \mathrm{Cl}$ & Adj. OR & $95 \% \mathrm{Cl}$ & Adj. OR & $95 \% \mathrm{Cl}$ \\
\hline \multicolumn{7}{|l|}{ Age } \\
\hline $18-24$ & Ref & Ref & Ref & Ref & Ref & Ref \\
\hline $25-44$ & 0.98 & $(0.34,2.78)$ & 0.77 & $(0.31,1.92)$ & 1.12 & $(0.48,2.58)$ \\
\hline $45-64$ & 1.63 & $(0.54,4.94)$ & 0.59 & $(0.19,1.88)$ & 0.83 & $(0.34,2.02)$ \\
\hline \multicolumn{6}{|l|}{ Race } & $(0.11,1.15)$ \\
\hline White & Ref & Ref & Ref & Ref & Ref & Ref \\
\hline Asian & 0.89 & $(0.13,5.88)$ & 0.43 & $(0.12,1.48)$ & 0.26 & $(0.05,1.48)$ \\
\hline Black & 0.62 & $(0.24,1.60)$ & 0.92 & $(0.26,3.23)$ & 0.67 & $(0.31,1.45)$ \\
\hline Hispanic & 0.74 & $(0.28,1.93)$ & 0.42 & $(0.16,1.10)$ & 1.08 & $(0.55,2.10)$ \\
\hline Other & 0.11 & $(0.03,0.44)$ & 0.26 & $(0.03,2.32)$ & 1.43 & $(0.55,3.69)$ \\
\hline \multicolumn{7}{|l|}{ Gender } \\
\hline Male & Ref & Ref & Ref & Ref & Ref & Ref \\
\hline Female & 1.87 & $(0.87,4.06)$ & 1.47 & $(0.76,2.86)$ & 0.94 & $(0.57,1.55)$ \\
\hline \multicolumn{7}{|l|}{ Education } \\
\hline$<$ High School & Ref & Ref & Ref & Ref & Ref & Ref \\
\hline High School Graduate & 1.41 & $(0.43,4.56)$ & 0.28 & $(0.10,0.81)$ & 0.84 & $(0.31,2.25)$ \\
\hline College Graduate & 2.57 & $(0.68,9.74)$ & 0.41 & $(0.13,1.26)$ & 1.26 & $(0.44,3.55)$ \\
\hline \multicolumn{7}{|l|}{ Income } \\
\hline$<\$ 30,000$ & Ref & Ref & Ref & Ref & Ref & Ref \\
\hline$\$ 30,000-\$ 75,000$ & 2.48 & $(1.03,5.95)$ & 0.53 & $(0.21,1.35)$ & 0.41 & $(0.22,0.77)$ \\
\hline \multirow{2}{*}{\multicolumn{7}{|c|}{ Marital status }} \\
\hline & & & & & & \\
\hline Married & Ref & Ref & Ref & Ref & Ref & Ref \\
\hline Not married & 2.00 & $(0.87,4.58)$ & 0.86 & $(0.37,2.04)$ & 1.86 & $(1.09,3.19)$ \\
\hline \multicolumn{7}{|l|}{ Past history of abuse } \\
\hline No & Ref & Ref & Ref & Ref & Ref & \\
\hline Yes & 2.44 & $(0.95,6.25)$ & 0.37 & $(0.03,3.90)$ & 3.68 & $(1.68,8.05)$ \\
\hline \multicolumn{7}{|c|}{ Previous mental health problem } \\
\hline No & Ref & Ref & Ref & Ref & Ref & Ref \\
\hline Yes & 5.64 & $(2.67,11.90)$ & 16.75 & $(5.94,27.24)$ & 12.11 & $(6.31,23.22)$ \\
\hline \multicolumn{7}{|l|}{ Health insurance } \\
\hline No & Ref & Ref & Ref & Ref & Ref & Ref \\
\hline Yes & 0.81 & $(0.25,2.63)$ & 0.34 & $(0.13,0.91)$ & 1.36 & $(0.46,3.99)$ \\
\hline \multicolumn{7}{|l|}{ Regular doctor } \\
\hline No & Ref & Ref & Ref & Ref & Ref & Ref \\
\hline Yes & 1.51 & $(0.44,5.17)$ & 3.50 & $(1.24,9.87)$ & 2.92 & (1.08. 7.92) \\
\hline \multicolumn{7}{|l|}{ Health status } \\
\hline Excellent, very good, good & Ref & & Ref & & Ref & \\
\hline Fair, Poor & 1.41 & $(0.66,3.02)$ & 3.16 & $(1.13,8.85)$ & 1.40 & $(0.67,2.95)$ \\
\hline \multicolumn{7}{|l|}{ Co-morbid conditions } \\
\hline 0 & Ref & Ref & Ref & Ref & Ref & \\
\hline 1 & 0.49 & $(0.22,1.09)$ & 2.16 & $(0.91,5.11)$ & 1.72 & $(0.98,3.01)$ \\
\hline $2+$ & 2.06 & $(0.87,4.85)$ & 2.80 & $(0.98,7.98)$ & 2.55 & $(1.17,5.56)$ \\
\hline
\end{tabular}

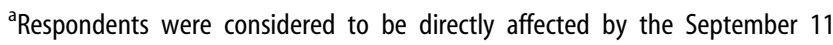
attacks if they were inside the WTC complex during the attacks, if they were injured during the attacks, if they lost possessions or property as a result of the

insurance coverage was not associated with professional help-seeking in these results in contrast to other studies [17], persons with higher incomes were more likely to seek services compared to persons with lower incomes raising concerns about financial barriers to care.

In this study we found that traditional barriers to mental health care identified in previous studies [1417] are also barriers to mental health service use after a major urban man-made disaster. However, barriers unique to the post-disaster context were also important for care seeking in this study. The barrier attacks, if a friend or relative was killed during the attacks, if they lost a job due to the attacks, or were involved in the rescue efforts

${ }^{\mathrm{b}}$ Two-tailed chi-square test of significance

most frequently reported as a reason for not utilizing services among persons who considered it was a concern that services are limited and that other people need them more. The idea that people would self-ration use of mental health services after a disaster is inconsistent with our current understanding of the U.S. public's beliefs about the rationing of health care services generally. Opinion polls in the U.S. show the public disapproving of placing limits on health care [36, 37]. Callahan (1992) writes that "symbolically the very idea [of rationing] seems to offend the nicely tinted picture 


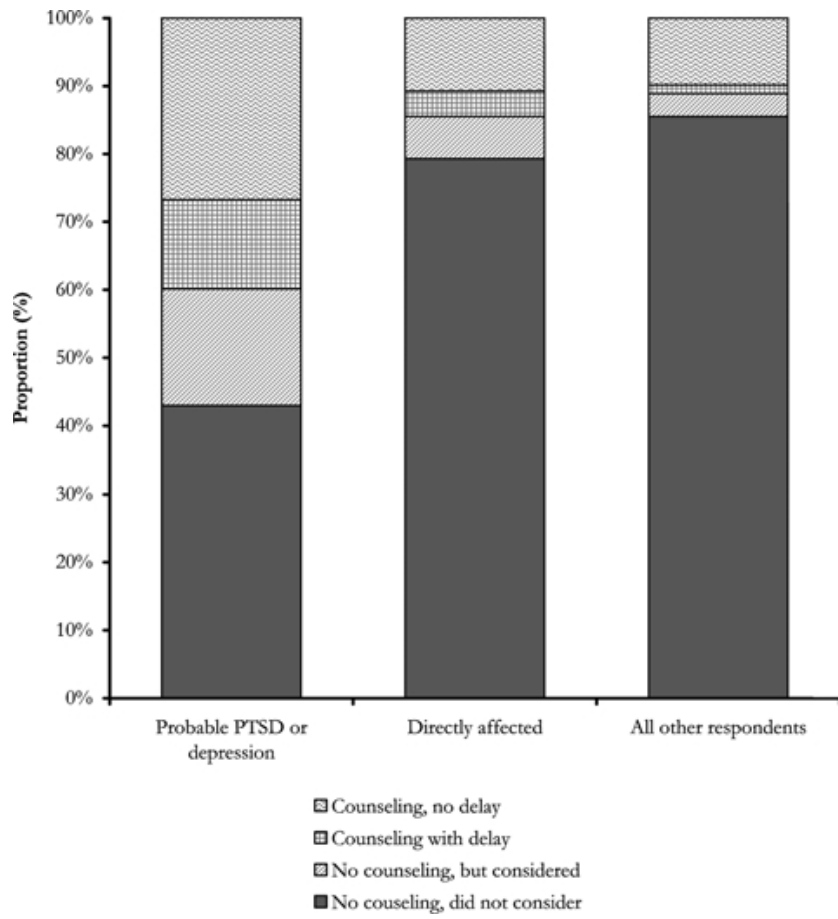

Fig. 1 Use of professional help among respondents with probable PTSD or depression $(n=419)$, those directly affected by the attacks but who do not have PTSD or depression ( $n=616$, respondents were considered to be directly affected by the September 11 attacks if they were inside the WTC complex during the attacks, if they were injured during the attacks, if they lost possessions or property as a result of the attacks, if a friend or relative was killed during the attacks, if they lost a job due to the attacks, or were involved in the rescue efforts) and all others ( $n=1,719$, bar graphs adjusted to $100 \%$ to show comparisons between groups

of ourselves as a rich, powerful nation, one that can afford to do whatever it takes to do whatever we want to do" [38]. In the months after the attacks the suffering of persons who were directly affected by the attacks and the angst of relatives who lost loved ones was widely publicized. Persons who were less affected may have felt reluctant to claim services out of a fear that they would be taking somebody else's spot. This behavior is consistent with the outpouring of support and charitable giving provided to the victims' families after the attacks [39]. In addition, a few respondents expressed feeling too overwhelmed and depressed to seek professional help and were afraid of discussing the events surrounding the September 11 attacks with a professional.

\section{Limitations}

Direct comparisons between our study and other studies of unmet mental health need must be made with caution because of methodologic differences between studies. Consistent with the majority of studies, we assessed mental health primarily using psychological symptoms consistent with DSM diagnostic psychiatric conditions [14, 15]. However, using psychological symptoms as the primary indicator of mental health need is limited insofar as persons with mental health problems may deny or minimize symptoms of mental illness, rationalize them as normal responses to life stresses or to other general medical problems, believe them to be failures of will or moral shortcomings or not within the physician's purview or capabilities [40]. As such, some studies have used subjective measures of perceived need $[15,41]$ or rely on individuals to report having received a diagnosis from a doctor for symptoms [42] as complementary measures of unmet need. Although subjective measures of perceived need are also limited because those who may benefit from services may not perceive that they need them, future studies of unmet mental health need after disasters should consider including both subjective assessments of need and measures of functioning.

It is likely that had we asked about barriers to mental health treatment in a completely open-ended fashion we would have received responses that have would been somewhat different than the ones we document here. The advantage to our approach was the ability to probe specific barriers without taking too much time to elicit responses. We note that respondents in our study had the option of volunteering other responses and that there were few responses offered beyond our pre-determined responses. Because this study is cross-sectional we are unable to portray the complex decision-making process that most people go through when deciding whether to seek professional help for mental health problems.

Ideally we would have examined the use of professionals for mental health problems among persons who screened positively for PTSD separately from persons who screened positive for depression. Larger studies are needed to examine the use of professionals among groups with different psychiatric conditions. We elected to create one group because we were interested in determining the use of mental health professionals among persons with psychiatric need in the period following September 11. Our estimate of unmet need in the NYC general population 6 months after the September 11 attacks is likely to be conservative because we did not measure other psychiatric disorders, which have been documented after other disasters such as anxiety disorder. Larger studies are also needed to examine predictors of the use of mental health professionals (e.g., psychiatrists) versus other health professionals (e.g., physicians) for mental health problems.

\section{Policy implications}

With respect to the question of whether there was unmet need for mental health services 6-9 months after the September 11 attacks, it is important to consider our findings in the light of research by Galea et al. (2003) showing that probable PTSD de- 
Fig. 2 Barriers to mental health care among respondents among respondents with probable PTSD or depression $(n=72)$, those directly affected by the attack but who do not have PTSD or depression $(n=38$, respondents were considered to be directly affected by the September 11 attacks if they were inside the WTC complex during the attacks, if they were injured during the attacks, if they lost possessions or property as a result of the attacks, if a friend or relative was killed during the attacks, if they lost a job due to the attacks, or were involved in the rescue efforts) and all others $(n=58)$

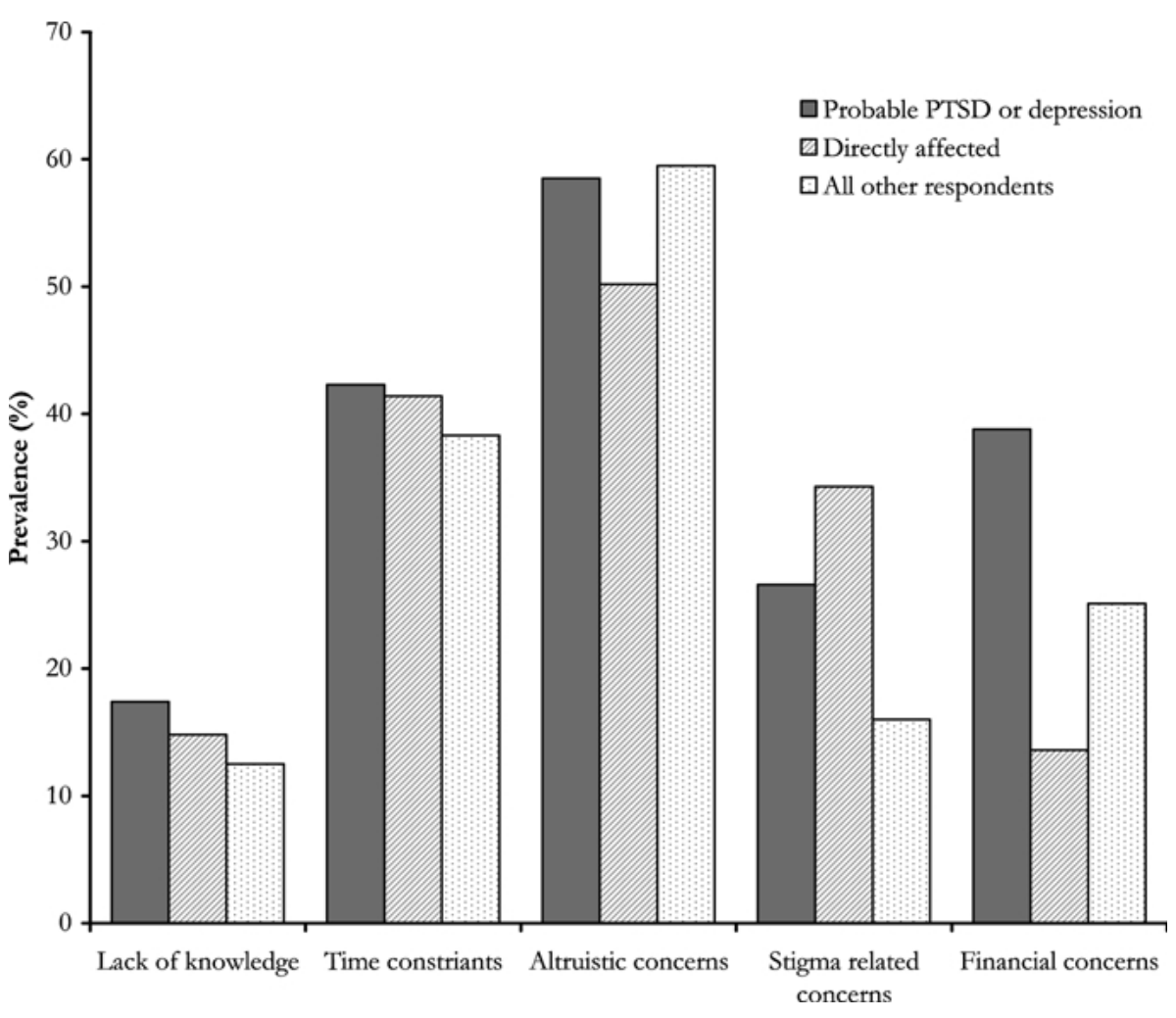

the vast majority of those who were directly affected also did not seek services. While the majority of these respondents did not meet the criteria for probable PTSD or depression, many had debilitating symptoms.

Recently, it has been recognized that rates of disorder based on brief screening assessments in community epidemiologic studies are insufficient to assess the need for services [45, 46]. Further research is needed to determine persons experiencing symptoms of PTSD and depression as well as high degrees of distress and loss of productivity who may benefit from mental health treatment. Our research when considered in the light of Galea et al. (2003) would suggest that there was unmet mental health need 6-9 months after the September 11 attacks, but that these findings should be tempered by the apparent decrease in population-rates of probable PTSD.

The question then remains what is the most effective way to respond to unmet mental health needs in a post-disaster context? The unmet need we identified undoubtedly reflects a combination of factors including: inadequate supply of mental health services, inadequate training of primary care providers to identify and make referrals to specialists for mental health problems, barriers to accessing the available supply (e.g., cost), as well as a lack of expected demand among potential users of these services. Thus, the expected fixes of these problems will also vary. For example, will allocating more resources to the mental health system after a disaster address 
unmet mental health needs? Is it more beneficial to target certain types of health providers in particular communities for these resources? Is more training of primary care providers needed to better equip primary care providers to identify signs of disorder, to treat and to make referrals for specialized mental health treatment? Is greater public education needed about the availability of services and to help people to recognize when they have symptoms of distress that can be treated?

We believe this study is useful because it calls attention to the problem of unmet mental health need in a post-disaster context and identifies some of the formidable barriers although it does less to suggest possible remedies. The shortcomings in the mental health response identified after the September 11 attacks have broader applicability to other urban areas and to other disasters (both terrorism related and to natural disasters). We recommend that policy makers, researchers, primary care providers and mental health providers continue to collaborate to improve NYC's mental health response after disasters and that these lessens be adapted to improve upon our nation's mental health response after disasters.

These results do not in anyway diminish the accomplishments of the Project Liberty program, which as of March 2002 reported providing services to over 91,000 individuals by way of crisis counseling sessions and public education [47]. It is unclear the extent to which those receiving Project Liberty services are new seekers of professional help for mental health problems or whether the persons utilizing the program had received services in the past. Providing services to both groups is important. Future studies should evaluate the overall impact of Project Liberty services on the burden of mental health symptoms in the NYC metropolitan area and the extent to which the Project Liberty model is sufficient as a model of mental health response after a major disaster in an urban area.

Acknowledgements Supported by grants from the National Institute of Mental Health (RO1 MH 66081-01), The United Way of New York City and the New York Community Trust.

\section{References}

1. Regier DA, Narrow WE, Rae DS, Manderscheid RW, Locke BZ, Goodwin FK (1993) The de factor US mental and addictive disorders system service: epidemiologic catchment area prospective 1-year prevalence rates of disorders and services. Arch Gen Psychiatry 50:85-94

2. Kessler RC, Zhao S, Katz SJ, Kouzis AC, Frank RG, Edlund M, Leaf P (1999) Past-year use of outpatient services for psychiatric problems in the national comorbidity survey. Am J Psychiatry $156: 115-123$

3. Norris FH (1992) Epidemiology of trauma: frequency and impact of different potentially traumatic events on different demographic groups. J Consult Clinical Psychol 60:409-418

4. Green BL (1991) Evaluating the effects of disasters. Psychol Assess 3:538-546
5. Schuster MA, Stein BD, Jaycox LH, Collins RL, Marshall GN, Elliott MN, Zhou AJ, Kanouse DE, Morrison JL, Berry SH (2001) A national survey of stress reactions after the September 11, 2001 terrorist attacks. New Engl J Med 345(20):1507-1512

6. Galea S, Ahern J, Resnick H, Kilpatrick D, Bucuvalas M, Gold J, Vlahov D (2002) Psychological sequelae of the September 11 terrorist attacks in New York City. New Engl J Med 346:982

7. Schlenger W, Caddeell JEL, Jordan B et al (2002) Psychological reactions to terrorist attacks: Findings from the National Study of Americans' reactions to September 11. J Am Med Assoc 288:581

8. Galea S, Vlahov D, Resnick H, Ahern J, Susser E, Gold J, Bucuvalas M, Kilpatrick D (2003) Progression of posttraumatic stress disorder symptoms among adults in New York City after the September 11 terrorist attacks. Am J Epidemiol 158(6):514524

9. Smith DW, Christiansen EH, Vincent R, Hann NE (1999) Population effects of the bombing of Oklahoma City. J Oklahoma State Med Assoc 92:193-198

10. Carr VJ, Lewin TJ, Carter GL, Webster RA (1989) Patterns of service utilization following 1989 Newcastle earthquake: findings form phase 1 of the quake impact. Aust J Public Health 16:330-369

11. Smith EM, North CS, McCool RE, Shea JM (1990) Acute postdisaster psychiatric disorders: identification of persons at risk. Am J Psychiatry 147:202-206

12. Boscarino JA, Galea S, Ahern J, Resnick H, Vlahov D (2002) Utilization of Mental Health Services following the September 11th Terrorist Attacks in Manhattan. Int J Emerg Mental Health 4(3):143-155

13. Boscarino JA, Galea S, Ahern J, Resnick H, Vlahov D (2003) Psychiatric medication use among New York City residents following a mass urban disaster: Implications for research and medical care. J Traumat Stress 16(3):301-306

14. Kessler RC, Berglund PA, Bruce ML, Koch JR, Laska EM, Leaf PJ, Manderscheid RW, Rosenheck RA, Walters EE, Wang PS (2001) The prevalence and correlates of untreated serious mental illness. Health Services Res 36(6 part I):987-1007

15. Majtabai R, Olfson M, Mechanic D (2002) Perceived need and help-seeking in adults with mood, anxiety, or substance use disorders. Arch Gen Psychiatry 59(1):77-84

16. McAlpine DD, Mechanic D (2002) Utilization of Specialty Mental Health Care among Persons with Severe Mental Illness: the roles of Demographics, Need, Insurance and Risk. Health Serv Res 35(1 part II):277-292

17. Mechanic D, (2002) Removing Barriers to Care among Persons with Psychiatric Symptoms. Health Affairs 21(3):137-147

18. Lindey JL, Grace MC, Green BL (1981) Survivors: Outreach to a reluctant population. Am J Orthopsychiatry 51(3):468-478

19. McFarlane AC (1985) Posttraumatic morbidity of a disaster: a study of cases presenting for psychiatric treatment. J Nerv Ment Dis 174(1):4-15

20. Wilkinson CB (1983) Aftermath of a disaster: the Collapse of the Hyatt Regency Hotel Skywalks. Am J Psychiatry 140:11341139

21. Schwart ED, Klowalski JM (1992) Malignant Memories: Reluctance to Utilize Mental Health Services After a Disaster. J Nervous Mental Dis 180(2):767-772

22. Wunsch-Hitzig R, Plapinger J, Draper J, del Campo E (2002) Calls for Help after September 11: a Community Mental Health Hot Line. J Urban Health 79(3):417-428

23. Rudenstine S, Galea S, Ahern J, Felton C, Vlahov D, (2003) Awareness and perceptions of a community-wide mental health program 4-5 months after the September 11 terrorist attacks in New York City. Psychiatric Serv 54(10):1404-1406

24. Mechanic D, McAlpine D, Rosenfield S, Davis D (1994) Effects of illness attribution and depression on the quality of life among persons with serious mental illness. Soc Sci Med 39(2): $155-164$

25. The American Association for Public Opinion Research (2000) Standard Definitions: Final Dispositions of Case Codes and Outcome Rates for Surveys. Ann Arbor, Michigan: AAPOR. 
http://www.aapor.org/default.asp?page=survey_methods/standards_and_best_practices/standard_definitions

26. American Psychiatric Association (1994) Diagnostic and statistical manual of mental disorders, 4th edn. American Psychiatric Association, Washington, DC

27. Kilpatrick DG, Resnick HS, Freedy JR, Pelcovitz D, Resnick PA, Roth S, van der Kolk B (1998) The posttraumatic stress disorder field trial: evaluation of the PTSD construct- criteria A through E. In: Widiger T, Frances A, Pincus $\mathrm{H}$ et al (eds) DSMIV sourcebook, vol 4. American Psychiatric Association Press Washington, DC 803-844

28. Resnick HS, Kilpatrick DG, Dansky BS et al (1993) Prevalence of civilian trauma and posttraumatic stress disorder in a representative national sample of women. J Consult Clin Psychol 61:984-991

29. Spitzer RL, Williams JB, Gibbon M (1987) Structured Clinical Interview for DSM-III-R-Non-patient Version. Biometrics Research Department, New York State Psychiatric Institute. New York, NY

30. Acierno R, Kilpatrick DG, Resnick H et al (2000) Assault, PTSD, family substance use, and depression as risk factors for cigarette use in youth: findings from the National Survey of Adolescents. J Traumat Stress 13:381-396

31. Kilpatrick DG, Ruggiero KJ, Acierno R et al (2003) Violence and risk of PTSD, major depression, substance abuse/dependence, and comorbidity: results from the national survey of adolescents. J Consult Clin Psychol 71(4):692-700

32. Galea S, Vlahov D, Tracy M, Hoover D, Resnick H, Kilpatrick DG (2004) Hispanic ethnicity and post-traumatic stress disorder after a disaster: evidence from a general populations survey after September 11. Ann Epidemiol 14(8):520-531

33. DeLisi L, Maurizio A, Yost M, Papparozzi C, Fulchino C, Katz C, Altesman J, Biel M, Lee J, Stevens P (2003) A survey of New Yorkers after the September 11, 2001 terrorist attacks. Am J Psychiatry 160:780-783

34. Beroff J, Kulka RA, Douvan E (1981)Mental health in America: patterns of help-seeking from 1957 to 1976. Basic Books, New York, NY
35. Rabinowtiz J, Gross R, Feldman D (1999) Correlates of a perceived need for mental health assistance and differences between those who do and do not seek help. Soc Psychiatry Psychiatr Epidemiol 34:141-146

36. Blendon RJ (1988) The public's views of the future of health care. J Am Med Assoc 259:3587

37. Jajich-Toth C, Roper, BW (1990) Americans' Views on Health Care: a Study in Contradictions. Health Affairs 9(4):149-157

38. Callahan D (1992) Symbols, rationality, and justice: rationing health care. Am J Law Med XVII(1,2):1-13

39. Independent Sector (2001) A survey of charitable giving after September 11th 2001. http://www.independentsector.org/PDF/ Sept11_giving.pdf

40. Goldman LS, Nielsen NH, Champion HC (1999) Awareness, diagnosis, and treatment of depression. J Gen Intern Med 14(9):569-580

41. Sherbourne CD, Dwight-Johnson M, Klap R (2001) Psychological distress, unmet need, and barriers to mental health care for women. Women's Health Issues 11(3):231-243

42. Roper Starch Worldwide Inc. (2001) America's Mental Health Survey. Prepared for the National Mental Health Association. www.nmha.org/pdfdoc/mentalhealthreport2001.pdf

43. Stein MB, Walker JR, Hazen AL, Forde DR (1997) Full and partial post-traumatic stress disorder: findings from a community survey. Am J Psychiatry 154:1114-1119

44. Marshall RD, Olfson M, Hellman F, Blanco C, Guardino M, Struening EL (2001) Comorbidity, impairment, and suicidality in subsyndromal PTSD. Am J Psychiatry 158:1467-1473

45. Bebbington PE (1990). Population surveys of psychiatric disorder and the need for treatment. Soc Psychiatry Psychiat Epidemiol15:33-40

46. Johnson S, Thornicroft G, Phelan M, Slade M (1996). Assessing needs for mental health services. In: Thornicroft G, Tansella M (eds). Mental health outcome measures. Springer-Verlag, Berlin pp. 217-226

47. Felton C (2002) Project Liberty: a public health response to the mental health needs of New Yorkers arising from the World Trade Center terrorist attacks. J Urban Health 79(3): 429-433 